\title{
8.2 Использование промышленных отходов в строительной индустрии эффективный способ сбережения природных ресурсов
}

Согласно последним данным экологов, Украина лидирует в Европе по количеству накопления отходов. Показатели образования и накопления отходов в Украине свидетельствуют об угрожающей экологической ситуации в государстве. По данным Министерства экологии и природных ресурсов Украины, в нашей стране накоплено около 35-36 млрд. тонн отходов, которые приблизительно занимают 7\% территории. Из этих 35-36 млрд. тонн около 2,6 млрд. тонн являются высокотоксичными отходами. Стоит отметить, что на каждого Украинца сейчас приходится более 750 тонн отходов. Ежегодно в Украине образуется от 670 до 770 млн. тонн, при этом утилизируется лишь 30\% промышленных и 4\% бытовых отходов [468-472].

Промышленные отходы и бытовые отходы являются одними из наиболее весомых факторов загрязнения окружающей среды и негативного влияния фактически на все его компоненты. Инфильтрация хранилищ захоронения бытовых и техногенных промышленных отходов, горения терриконов, пылеобразования, другие факторы, обусловливающие миграцию токсичных веществ, приводят к загрязнению подземных и поверхностных вод, ухудшение состояния атмосферного воздуха, земельных ресурсов и т.д. [473-476].

Будущие перспективы развития предприятий промышленности строительных материалов находятся на стадии коренной переоценки в связи с острым дефицитом энергетических ресурсов. Для решения проблем по снижению себестоимости конечной продукции строительства и сокращению расходов сырья, топливно-энергетических и других ресурсов, особая роль отводится расширению использования, как промышленных отходов, так и бытовых [477-479].

Проблемам образования и рационального использования отходов, как составляющей ресурсосбережения и экологизации производства, посвящено много научных работ. Однако недостаточность исследований данной проблематики, вызывает ряд проблем в сфере использования промышленных и 
твердых бытовых отходов (ТБО) и обусловливает необходимость дальнейших исследований в этом направлении.

В "Лаборатории ресурсосберегающих технологий и специальных бетонов" Винницкого национального технического университета (ВНТУ) проводятся исследования по комплексной переработке фосфогипсових отходов, золы-уноса, красного бокситового и металлических шлемов, а также твердых бытовых отходов. Целью данных исследований является разработка новой безотходной технологии переработки промышленных отходов с последующим получением эффективного малоклинкерного вяжущего и строительных материалов специального назначения.

Задача прироста прочности строительных изделий может решаться эффективными традиционными технологическими приемами - за счет использования комплексных химических и активных минеральных добавок. Но если использование в составе сырьевых смесей активных природных минеральных добавок потребует дополнительных затрат на их производство, то 12 тепловых электрических станций, эксплуатируемых в Украине ежегодно направляются в отвалы 10 млн. тонн золы-уноса (ЗУ). Удельный вес использования такого сырья техногенного происхождения отечественными предприятиями строительных материалов в 5-8 раз меньше, чем в зарубежных странах $[478,480]$.

Зола-уноса - это тонкодисперсный материал, состоящий, как правило с частиц размерами от доли микрона до 0,14 мм.. Основным компонентом ЗУ является стекловидная алюмосиликатная фаза, которая содержит 40-65 \% всей массы, ее частицы имеют шарообразную форму с размерами до 100 мкм [481].

В работах [482-483] авторами установлено, что основные составляющие золы - $\mathrm{SiO} 2, \mathrm{Al} 2 \mathrm{O} 3$ находятся преимущественно в виде стекловидных фаз. В результате проведенных исследований было установлено, что активность золы возрастает с увеличением содержания стекловидных фаз.

Одним из перспективных исследовательских направлений ВНТУ является активация золошлаковых отходов, для дальнейшего их использования в 
производстве строительных материалов. На наш взгляд, химическая активация золы-уноса кислыми остатками фосфогипса или щелочной средой красного шлама есть наименее энергоемкой, эффективной и экологически чистой технологией переработки промышленных отходов.

Комплексный метод механо-химической активации золы-уноса (ЗУ) предполагает разрушение поверхности стекловидной оболочки частиц путем использования остатков кислот с фосфогипса или ее растворением в щелочной среде красных шламов с одновременным перемешиванием смеси. Применение механического перемешивания золошламовой и золофосфогипсовой смесей способствует более полной активации ЗУ [484-485].

Фосфогипсовые отходы являются побочным продуктом при производстве фосфорной кислоты экстракционным способом. Химический состав фосфогипса Винницкого ПО "Химпром "следующий : $\mathrm{CaO}$ 7,42-12,8\%; SO3 2,41-6,25\%; F 3,55-5,81\%; P2O5 14,49-21,18\%; P3 13,21-15,78\% ; Н2О 9,76-16,07\%, остаток соляной кислоты - 6,66- 17,7\% [486].

Дифференциально-термические анализы (ДТА) цементного камня с разным количеством золы, обычной и обработанной кислыми стоками фосфогипса, а также контрольного образца без добавки золы-унос показывают, что на кривых ДТА зафиксированы такие термические эффекты: раздвоенный эндотермический эффект в интервале температур $100-120$ C с максимумами при 105-150 и $180{ }^{\circ} \mathrm{C}$, указывающий на удаление адсорбционной воды из гидратных новообразований. Резкий эндоэффект с максимумом при 500-520 ㄷ связан с дегидратацией гидроксида кальция - $\mathrm{Ca}(\mathrm{OH}) 2$. Размытый экзотермический эффект при $880-905^{\circ} \mathrm{C}$ свидетельствует о наличии низкоосновных гидросиликатов кальция, скорее всего гидросиликатного геля. В образцах с активированной золой на кривой ДТА можно увидеть более глубокий эндоэффект, чем у образца с не активированной золой, подтверждающий наличие значительно большего количества гидратных новообразований.

Рентгенофазовые исследования цементных и золоцементного образцов (рис. 1) указывают на наличие в их составе негидратованих клинкерных 
минералов C3S - линии с межплоскостными расстояниями $\mathrm{d} / \mathrm{n}=3,02 ; 2,77 ; 2,75$ 2,$18 ; 1,76 ; 1,45$ А ; C2S - линии с d / n = 2,77; 2,18; 1,97 1,76; 1,45 A; Ca (OH)2 линии с d/ n $=4,90 ; 3,10 ; 2,621,92 \mathrm{~A} ; \mathrm{CaC03} \mathrm{-} \mathrm{линии} \mathrm{с} \mathrm{d} \mathrm{/} \mathrm{n} \mathrm{=1,82} \mathrm{А;} \mathrm{кварца} \mathrm{-}$ линии $\mathrm{d} / \mathrm{n}=3,34$ А. Кроме того, отмечаются линии, характерные для гидратных новообразований - низкоосновных гидросиликатов кальция (CSH) - d / n $=3,08$ A.

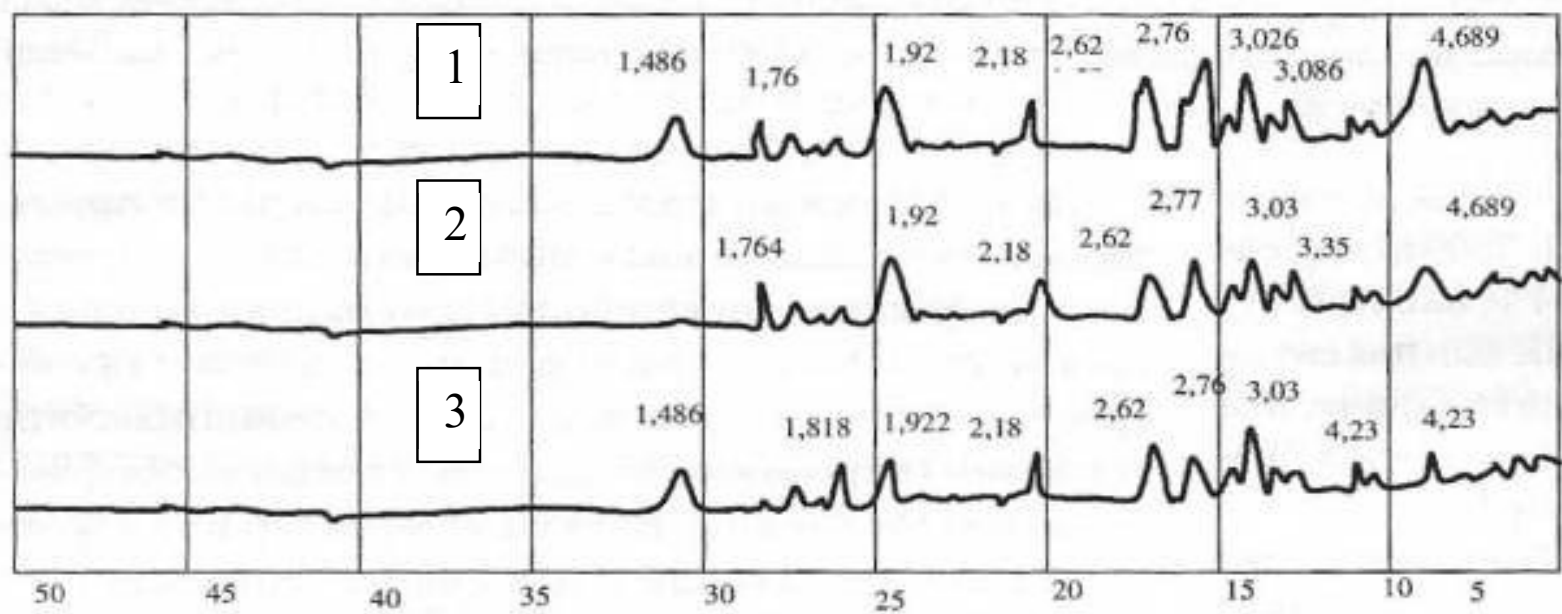

Рис. 1. Рентгенограммы опытных образцов: 1 - цементный образец; 2 - цементный образец с добавкой $30 \%$ не активированной 3У; 3 - цементный образец с добавкой $30 \%$ химически активированной $3 У$.

В золоцементных образцах с добавкой активизированной золы (образец 3) появляются комплексные алюминий-железогидросульфосодержащие соединения кальция, для которых характерны линии с $\mathrm{d} / \mathrm{n}=2,45 ; 3,07 ; 4,22 ; 7,62$ А. Наличие таких новообразований в составе золоцементных образцов можно объяснить тем, что во время химической активации ЗУ образуются сульфаты алюминия и железа. Рентгенограммы и ДТА подтверждают наличие таких солей и возможность их участия в процессах твердения вяжущего.

Красный бокситовый шлам обладает достаточно высокой щелочной средой. Поэтому использование красных шламов для химической активации ЗУ также приводит к разрушению стеклообразной поверхности золошамовых отходов, что дает возможность экономить высокоэнергоемкий компонент строительной смеси - цемент. Авторами в работах [483-485] доказано, что добавление бокситового шлама в состав золоцементной смеси обеспечивает 
интенсификацию процессов новообразований минерально-фазового состава и обеспечивает экономию минерального вяжущего.

В работе [487] доведено, что основным направлением утилизации красного шлама при производстве строительных материалов является его использование в качестве модифицирующей добавки к золоцементному вяжущему, введение бокситового шлама существенно влияет на изменение новообразований золоцементого камня.

Необходимо учитывать, промышленные отходы могут широко применяться для получения специальных строительных материалов [488]. К специальным материалам разработанным у ВНТУ можно отнести композиционный бетон с защитными свойствами от электромагнитных излучений [489], статического электричества [490], анодные заземлителели для защиты подземных инженерных сооружений [491].

В работах [492-493] подтверждено, что применение Бэтела-м ячеистой, вариотропной и плотной структуры дает возможность снизить уровень электромагнитных излучений, а ячеистый электропроводный композиционный металанасыщенный бетон является эффективным радиопоглощающим материалом. В качестве электропроводного компонента целесообразно использовать металлический шлам шарикоподшипникового производства. Такой шлам не подлежит дальнейшей переработке, так как на своей поверхности содержит большое количество охлаждающей жидкости, которая состоит из эмульсии масла [494].

В статье [495] установлено, что меняя вид электрического тока, его величину и длительность протекания можно управлять физико-химическими процессами во время твердения композиционного металопроводного бетона, а следовательно, и электрическими характеристиками Бэтела в нужном направлении.

В работах [495-496] обоснована целесообразность применения мелкодисперсных порошков шламов стали ШХ-15 для изготовления специального защитного покрытия. В работе [497] предложено использовать для 
борьбы с зарядами статического электричества покрытие с электропроводящего бетона, технология изготовления которого довольно проста и не требует дорогих материалов и специального оборудования. Установлено, что для получения антистатического покрытия, соответствующего требованиям электропроводности, физико-механическим и эстетическим требованиям, необходимо изготавливать покрытия на крупном диэлектрическом наполнителе.

Авторы в работе [498] подтверждают, что Бэтел-м может использоваться для изготовления электропроводящих элементов (анодных заземлителей) систем антикоррозионной катодной защиты подземных инженерных сетей, a формирование таких изделий необходимо проводить используя одновременное воздействие на приготовленную смесь электромагнитного и механического способа. Формирование изделий таким способом обеспечивает улучшение физико-механических и электрофизических свойств элементов анодных заземлителей.

В результате проведенных аналитических исследований установлено:

- производство строительных материалов относится к числу наиболее материалоемких отраслей промышленности, использования промышленных отходов в качестве сырья при изготовлении строительных материалов может быть использовано для существенного снижения темпов исчерпания природных ресурсов;

- промышленные отходы успешно можно использовать для создания безклинкерного вяжущего и материалов специального назначения. 